\title{
A CROSS CULTURAL INVESTIGATION OF THE STEREOTYPE FOR SALESPEOPLE
}

Christophe Fournier IAE MRM Université Montpellier 2 - France

Emmanuel Chéron Akita International University - Japan

John F Tanner Jr., Hankamer School of Business, Baylor University - United States of America

Pierre J Bikanda Université Catholique d'Afrique Centrale - Cameroon

Jorge A. Wise, ITESM - Campus Cuernavaca - Mexico

\begin{abstract}
The purpose of this research is to investigate the image of salespeople and of the selling function as perceived by business students across several cultures. Of the several empirical investigations that exist in the sales literature, most consider samples from a single country. A quantitative survey conducted on students living in five countries (Cameroon, France, Japan Mexico and United States) was implemented. A significant culture effect was observed on salesperson's image, feelings in presence of a salesperson as well as perception of a career in sales. The implications of the findings are discussed for sales education, hiring practices, and research.
\end{abstract}

References Available Upon Request 